\title{
Control of Fusarium Wilt of Watermelon by Grafting onto Bottlegourd or Interspecific Hybrid Squash Despite Colonization of Rootstocks by Fusarium
}

\author{
A. P. Keinath and R. L. Hassell, Clemson University, Coastal Research and Education Center, Charleston, SC 29414
}

\begin{abstract}
Keinath, A. P., and Hassell, R. L. 2014. Control of Fusarium wilt of watermelon by grafting onto bottlegourd or interspecific hybrid squash despite colonization of rootstocks by Fusarium. Plant Dis. 98:255-266.

Grafting watermelon (Citrullus lanatus var. lanatus) onto rootstocks of interspecific hybrid squash (Cucurbita moschata $\times$ C. maxima), bottle gourd (Lagenaria siceraria), or citron (Citrullus lanatus var. citroides) has been used in Asia and Israel to mange Fusarium wilt of watermelon caused by Fusarium oxysporum f. sp. niveum. The objectives of this study were to determine the frequency of infection of six rootstocks by $F$. oxysporum f. sp. niveum races 1 and 2 and the field performance of grafted rootstocks in Charleston, SC. Grafted and nongrafted watermelon and rootstock plants were inoculated in the greenhouse with race 1 , race 2 , or water (the control treatment). With both races, the frequency of recovery of $F$. oxysporum from scion and rootstock portions of inoculated watermelon plants grafted onto 'Ojakkyo' citron was greater than from watermelon plants grafted onto 'Shintosa Camel' and 'Strong Tosa' interspecific hybrid squash, and from plants grafted onto 'Emphasis', 'Macis', and 'WMXP 3945' bottlegourd. For nongrafted plants inoculated with race 1 , percent recovery also was greater from Ojakkyo than from interspecific hybrid squash and bot-

tlegourd. For nongrafted plants inoculated with race $2, F$ oxysporum was recovered from the base of $\geq 79 \%$ of all inoculated plants. More than two-thirds (15) of 21 isolates recovered from the tops or scions of inoculated plants were pathogenic on watermelon. In spring 2010 and 2011, the six rootstocks were grafted with seedless watermelon 'Tri-X 313', which is susceptible to both races, and transplanted in a field infested with races 1 and 2 of $F$. oxysporum f. sp. niveum. Disease incidence for nongrafted and self-grafted Tri-X 313 (the control treatments) and Tri-X 313 grafted onto Ojakkyo citron did not differ significantly. Grafted watermelon plants produced greater weights and numbers of fruit than plants of the two control treatments. Nonpathogenic isolates of $F$. oxysporum and isolates of $F$. oxysporum $\mathrm{f}$. sp. niveum colonized interspecific hybrid squash, bottlegourd, and grafted watermelon. The rootstocks evaluated, however, restricted movement of $F$. oxysporum f. sp. niveum into the watermelon scion, suppressed wilt symptoms, and increased fruit yields in an infested field.
\end{abstract}

Fusarium wilt is a widespread, damaging disease of watermelon (Citrullus lanatus var. lanatus) throughout the United States, Turkey, and other watermelon-producing countries $(26,44,45)$. Cropping the same fields to watermelon without adequate rotation to other crops or use of soil fumigants selects for and increases the population density of the specialized form of the soilborne fungus Fusarium oxysporum, $F$. oxysporum f. sp. niveum, that infects watermelon (12,32). Fusarium wilt results in the death of individual vines or whole plants, directly reducing the number of fruit produced (15). In addition, the pathogen persists indefinitely in infested soil $(30,36)$. The four races of $F$. oxysporum $\mathrm{f}$. sp. niveumraces $0,1,2$, and 3 -are identified by virulence on differential watermelon cultivars $(29,49)$. Race 0 is pathogenic only on older or heirloom watermelon cultivars that have no resistance. Most hybrid, diploid, seeded cultivars have resistance to race 1 . Race 2 is present in all major watermelon-producing states in the United States (18). In 2010, race 3 was found in Maryland (49).

Traditionally, 7- to 12-year rotations have been recommended to manage Fusarium wilt $(30,36)$. Many watermelon growers specialize in watermelon production and cannot leave land out of produc-

\section{Corresponding author: A. P. Keinath, E-mail: tknth@clemson.edu}

This material is based upon work supported by NIFA/United States Department of Agriculture under project numbers SC-1700446 and SC-1700366. Technical Contribution Number 6107 of the Clemson University Experiment Station.

* The $\boldsymbol{e}$-Xtra logo stands for "electronic extra" and indicates that Figure 1 appears in color in the online edition.

Accepted for publication 7 September 2013.

http://dx.doi.org/10.1094/PDIS-01-13-0100-RE

(C) 2014 The American Phytopathological Society tion for more than 1 or 2 years (47). In South Carolina, because all seedless watermelon and a majority of seeded watermelon crops are irrigated, growers are limited to planting in fields equipped with wells, pumps, or center-pivot irrigation. Although diploid, seeded watermelon cultivars resistant to race 1 were used in the past to manage this disease, the watermelon market has shifted to seedless fruit (R. L. Hassell, unpublished data). Most seedless, triploid cultivars are susceptible to Fusarium wilt caused by $F$. oxysporum f. sp. niveum race 1 , and all diploid and triploid watermelon cultivars are susceptible to $F$. oxysporum $\mathrm{f}$. sp. niveum races 2 and 3 (18). Soil fumigants, such as methyl bromide applied with various percentages of chloropicrin and 1,3-dichloropropene plus $35 \%$ chloropicrin, have been used to manage Fusarium wilt with varying degrees of success $(15,35)$. Additional worker protection and environmental safety requirements for the use of soil fumigants initiated by the United States Environmental Protection Agency in 2010 have made use of these pesticides more costly and time-consuming (41).

Grafting watermelon is done in various countries, notably Korea, Japan, and Israel, to combat soilborne pathogens and increase yield $(3,22,26,27)$. The two most common rootstocks used for grafting watermelon are cultivars of an interspecific hybrid squash (Cucurbita moschata $\times$ C. maxima) and cultivars of bottle gourd (Lagenaria siceraria) that were bred specifically for use as rootstocks $(19,43)$. Citron (Citrullus lanatus var. citroides) is being tested as another rootstock because some genotypes have resistance to rootknot nematode (39). Because $F$. oxysporum f. sp. niveum was defined as host-specific to watermelon, the fungus does not cause Fusarium wilt on other cucurbits $(30,49)$. Resistance to Fusarium wilt in cucurbit rootstocks should prevent Fusarium wilt in the watermelon scion. However, F. oxysporum f. sp. niveum has been reported to infect a few other cucurbits, including seedlings and young plants of several summer squash (Cucurbita pepo) cultivars (31). In Tunisia, several cultivars of interspecific hybrid squash used as rootstocks were susceptible (i.e., had $>30 \%$ wilted plants) 
when inoculated in the greenhouse with Tunisian isolates of $F$. oxysporum $\mathrm{f}$. sp. niveum (1). Thus, it is possible that $F$. oxysporum f. sp. niveum could infect rootstocks and move into the scion, causing symptoms of Fusarium wilt. The frequency of such scion colonization is unknown but should be determined to assess the potential effectiveness of grafting watermelon onto cucurbit rootstocks to manage Fusarium wilt. The objectives of this study were to (i) evaluate infection by $F$. oxysporum $\mathrm{f}$. sp. niveum of different genera of cucurbit rootstocks and of watermelon grafted onto these rootstocks and (ii) evaluate control of Fusarium wilt in a field naturally infested with $F$. oxysporum $\mathrm{f}$. sp. niveum using watermelon grafted onto cucurbit rootstocks.

\section{Materials and Methods}

Rootstocks and grafting procedure. Six rootstocks were grafted with seedless watermelon Tri-X 313 (Syngenta Seeds; Table 1). All seed were sown in 72-cell plug trays with cell depth of $5.7 \mathrm{~cm}$, cell bottom diameter of $2.5 \mathrm{~cm}$, and cell top diameter of $4.0 \mathrm{~cm}$ (TLC Polyform) filled with a fertilizer-free, soilless mix (76\% sphagnum peat and $25 \%$ perlite) provided by Sun Gro Horticulture. No fertilizer was applied during the experiments. Seeding of the different cultivars was staggered to ensure that the hypocotyls of all varieties were the appropriate diameter $(3 \mathrm{~mm})$ when grafted, and rootstocks were at the appropriate developmental stage (tip of the first true leaf just beginning to emerge) to minimize regrowth of the tops of rootstocks (11). Watermelon, used as the scion, was seeded first. Flats were placed on a heating pad set at $32^{\circ} \mathrm{C}$, covered with black polyethylene film for $48 \mathrm{~h}$ to induce germination, and then removed from the heating pad and placed in a greenhouse at $24^{\circ} \mathrm{C}$. When the cotyledons of the scion material had fully expanded, the bottlegourd rootstock cultivars and 'Ojakkyo' were seeded and incubated in the greenhouse. When the bottlegourd seedlings had emerged (usually 3 days after seeding), the interspecific squash hybrid cultivars were seeded.

Approximately 10 days after seeding the squash, when the watermelon scion was at the first true-leaf stage, the watermelon was grafted onto the rootstocks using the one-cotyledon grafting method (11). Grafted plants were maintained in a healing chamber with $90 \%$ humidity at $24^{\circ} \mathrm{C}$ for 7 days, then grown on a greenhouse bench for an additional 7 days. In order to determine whether the grafting procedure, which included wounding and healing phases, had an effect on infection of the scion by $F$. oxysporum f. sp. niveum, a self-grafted control treatment was included in the second experiment, with inoculations using both races of the pathogen, in which Tri-X 313 seedlings were used as both the scion and the rootstock.

Greenhouse inoculations. Grafted and nongrafted plants were inoculated in the greenhouse 14 days after grafting with an isolate of $F$. oxysporum f. sp. niveum race 1 or an isolate of race 2. In total, eight separate inoculation experiments were done: four experiments with nongrafted plants and four experiments with rootstocks grafted with seedless watermelon. Of the eight experiments, four were with race 1 and four with race 2 . Details are presented below.

F. oxysporum f. sp. niveum isolate B05-07, which was identified previously as race 1 , and isolate $\mathrm{B} 05-30$, which was identified previously as race 2 , originated from naturally infected mini-water- melon cultivars grown at the Clemson University Coastal Research and Education Center (CREC) $\left(32^{\circ} 47^{\prime} 30.4 \mathrm{~N}, 80^{\circ} 4^{\prime} 11.16 \mathrm{~W}\right)$ in $2005(14,16)$. To prepare inoculum, isolates were grown on quarter-strength potato dextrose agar (PDA) for 7 to 10 days. Three 1$\mathrm{cm}^{2}$ pieces of agar with mycelium of the appropriate isolate were added to $100 \mathrm{ml}$ of potato dextrose broth (PDB), and grown on a shaker table at $125 \mathrm{rpm}$ for 7 days at $24^{\circ} \mathrm{C}$. The broth was filtered through two layers of sterile cheesecloth. Spores were counted on a hemocytometer and the concentration was adjusted to $10^{6}$ microconidia/ml.

To inoculate grafted plants, the roots were rinsed gently to remove most of the adhering potting medium and dipped for $10 \mathrm{~s}$ in the microconidial suspension. Each plant was transplanted into a separate $7.5-\mathrm{cm}$-diameter pot $(8.5 \mathrm{~cm}$ tall) in Fafard 3B potting soil. The experimental design was a randomized complete block with 20 replications of individual plants; each plant served as an experimental unit. Nongrafted 'Allsweet' watermelon, resistant to $F$. oxysporum $\mathrm{f}$. $\mathrm{sp}$. niveum race 1 and susceptible to race 2 , and Tri-X 313 , susceptible to both races, were included as inoculated control treatments (45). In the second experiments with both races, selfgrafted Tri-X 313 was included as a grafting control treatment. Roots of noninoculated control plants were dipped in water for $10 \mathrm{~s}$. In the first experiments with both races, 10 noninoculated plants of each cultivar were used and, in the second experiments, 20 noninoculated plants per cultivar were used. Plants were maintained in the greenhouse at 24 to $27^{\circ} \mathrm{C}$ for 3 weeks. Disease incidence based on symptoms of wilting was recorded 14 and 21 days after inoculation.

In separate experiments, nongrafted plants of the same cultivars were inoculated with both races of $F$. oxysporum $\mathrm{f}$. sp. niveum. In these experiments, four plants per pot were transplanted, with five replicate pots, for a total of 20 inoculated and 20 noninoculated plants per cultivar. The cultivars were seeded in the same sequence as the plants used for grafting, inoculated using the same procedure described above, and evaluated 14 and 21 days after inoculation. Allsweet and Tri-X 313 were included as control treatments, except that, in the first experiment with race 2, the diploid susceptible 'Black Diamond' was used in place of Tri-X 313 (Table 1).

At the termination of each experiment 21 days after inoculation, two $0.5-\mathrm{cm}$-diameter pieces were cut from the base of the main stem of each plant starting approximately $1 \mathrm{~cm}$ above the soil line, and two pieces of the stem were cut from between the first and second true leaf of each plant. Thus, on grafted plants, the base of the rootstock and the top of the watermelon scion were sampled whereas, on nongrafted plants, pieces were cut from the base and top of the same plant. In this context, "scion" refers to the top of a grafted plant and "top" refers to the top of a nongrafted plant. Pieces were surface disinfested for $30 \mathrm{~s}$ with $0.5 \%$ sodium hypochlorite, rinsed in sterile water, and placed on Komada's agar medium to determine whether $F$. oxysporum was present in the piece (20). Plates were held at 20 to $22^{\circ} \mathrm{C}$ with 16-h day length. After 8 to 9 days, colonies resembling $F$. oxysporum were counted based on color (white to pale orange or salmon) and texture (dense and fluffy) of aerial mycelium and abaxial colony color (dull purple to purple-brown) (20). The top or base of the plant was considered infected if one or both of the pieces yielded a colony that resembled F. oxysporum.

Table 1. Cultivars of watermelon and cucurbit rootstocks used in this study in Charleston, SC to evaluate for control of Fusarium wilt of watermelon caused by Fusarium oxysporum f. sp. niveum

\begin{tabular}{|c|c|c|c|c|}
\hline Cultivar & Species & Common name & Source & Abbreviation \\
\hline Tri-X 313 & Citrullus lanatus var. lanatus & Seedless, triploid watermelon & Syngenta Seeds, Boise, ID & TX \\
\hline Allsweet & C. lanatus var. lanatus & Seeded, diploid watermelon & Everwilde Farms, Sand Creek, WI & AS \\
\hline Black Diamond & C. lanatus var. lanatus & Seeded, diploid watermelon & Everwilde Farms, Sand Creek, WI & BD \\
\hline Emphasis & Lagenaria siceraria & Bottlegourd & Syngenta Seeds, Boise, ID & EM \\
\hline Macis & L. siceraria & Bottlegourd & Nunhems USA, Parma, ID & MA \\
\hline WMXP 3945 & L. siceraria & Bottlegourd & Harris Moran Seed Co., Modesto, CA & WX \\
\hline Shintosa Camel & Cucurbita moschata $\times$ C. maxima & Interspecific hybrid squash & Nunhems USA, Parma, ID & $\mathrm{SC}$ \\
\hline Strong Tosa & C. moschata $\times$ C. maxima & Interspecific hybrid squash & Syngenta Seeds, Boise, ID & ST \\
\hline Ojakkyo & Citrullus lanatus var. citroides & Citron & Syngenta Seeds, Boise, ID & OJ \\
\hline
\end{tabular}


Pathogenicity tests. Isolates of $F$. oxysporum recovered from noninoculated plants (73 isolates) or inoculated plants (30 isolates) were checked for pathogenicity to seedlings of 'Sugar Baby' watermelon, which is very susceptible to all races of $F$. oxysporum $\mathrm{f}$. sp. niveum (45). Between 3 and 24 isolates were saved from each experiment for pathogenicity testing. The rapid pathogenicity assay described by Zhou and Everts (45) was used, except that three seeds in each of two cells of a 128-cell tray were inoculated with each isolate instead of seeds in one cell. In all tests, the race 1 and 2 isolates used in the inoculation experiments were included as control treatments. Noninoculated seed were treated similarly with water. At 14 days after inoculation and seeding, isolates were considered pathogenic if at least one seedling in each inoculated cell (i.e., at least two of the six seedlings) showed symptoms of wilting.

Field experiments. A preliminary evaluation of grafted watermelon was done in spring 2006 at the CREC, Charleston, SC in a field of Yonges loamy fine sand with $\mathrm{pH}$ 6.2. The field was cropped to watermelon the two previous seasons. Symptoms of Fusarium wilt were present in both crops, and $F$. oxysporum $\mathrm{f}$. sp. niveum races 1 and 2 were present in the field (35). After disking on 7 March 2006, 10N-10P-10K was broadcast at $897 \mathrm{~kg} / \mathrm{ha}$ within the rows, and beds were cultivated lightly with a rotovator, shaped 0.9 $\mathrm{m}$ wide on $2.7-\mathrm{m}$ centers, and covered with black polyethylene mulch. The herbicide ethalfluralin + clomazone (Strategy 2.1EC; Loveland Products) was applied to the alleys between beds at 1.76 $\mathrm{kg} / \mathrm{ha}$ on 29 March 2006. The seedless mini-watermelon 'Vanessa' (Sunseeds, now Nunhems USA) was grafted onto 'Emphasis' and 'Macis' bottlegourd and the interspecific hybrid squash 'RS1330' and 'RST04109W', or was not grafted. Transplants were set $0.6 \mathrm{~m}$ apart in every other row on 30 March 2006. The herbicide halosulfuron-methyl (Sandea; Gowan) was applied to the alleys at $39 \mathrm{~g} / \mathrm{ha}$ on 12 May 2006. Cucumber beetles and pickle worms were controlled with esfenvalerate (Asana XL; DuPont Crop Protection) at $34 \mathrm{~g} / \mathrm{ha}$ on 9 June. Liquid $8 \mathrm{~N}-0 \mathrm{P}-8 \mathrm{~K}$ fertilizer was applied daily to the field through the drip irrigation system, beginning 1 week after transplanting (18). The experimental design was a randomized complete block with six replications. Plots were one row wide and $4.6 \mathrm{~m}$ long with $3.0 \mathrm{~m}$ of nonplanted space between plots within rows. Plants with Fusarium wilt symptoms were counted on 23 May and 5 and 27 June 2006. At the last rating, vines from 12 symptomatic plants, two or more plants per treatment from two different blocks, were cultured on Komada's agar medium as described previously, except that stem pieces were disinfested for $1 \mathrm{~min}$.

In spring 2010 and 2011, the six rootstocks used in the greenhouse experiments were tested in two field experiments after being grafted to seedless watermelon Tri-X 313. The experiments were conducted at the CREC in a field known to be infested with $F$. oxysporum f. sp. niveum races 1 and $2(14,16)$. In 2010, the naturally occurring inoculum was supplemented with additional inoculum prepared using the race 1 and race 2 isolates used in the greenhouse experiments. These isolates originated from watermelon cropped in the same field in 2005. Inoculum was prepared for each isolate in two clear, autoclavable bags filled with 5 liters of perlite that had been saturated with 2.5 liters of PDB (7). The bags of perlite-broth mixture were autoclaved for $1 \mathrm{~h}$ on each of two consecutive days. A microconidial suspension and one $10-\mathrm{cm}-$ diameter plate of PDA with mycelium of the appropriate fungal isolate, cut into pieces, were added to each of the bags, which were incubated at $25^{\circ} \mathrm{C}$ for 10 days. Inoculum concentration was estimated by dilution plating a suspension of $1 \mathrm{~g}$ of perlite in $9 \mathrm{ml}$ of sterile, deionized water onto one-quarter-strength PDA, and by placing 30 pieces of perlite from each bag onto water agar amended with streptomycin at $100 \mathrm{mg} / \mathrm{liter}$. Inoculum concentration of the race 1 and race 2 isolates was $1.0 \times 10^{5}$ and $4.3 \times 10^{4}$ $\mathrm{CFU} / \mathrm{g}$, respectively. All 120 pieces of perlite cultured yielded colonies of $F$. oxysporum that resembled the original isolates. Inoculum of the two isolates was combined. In 2010 only, $15 \mathrm{ml}$ $(10 \mathrm{~g})$ of inoculum with a mean concentration of $7.3 \times 10^{5} \mathrm{CFU} / \mathrm{g}$ was added to the transplanting hole immediately before transplanting.
The field was cropped to watermelon in spring 2009 and was seeded to rye in November 2010. The soil type was Yonges loamy fine sand with a $\mathrm{pH}$ of 6.4. Prior to bedding, the field was disked twice each spring. On 6 April 2010 and 14 March 2011, raised beds were shaped $0.9 \mathrm{~m}$ wide on $2.7-\mathrm{m}$ centers with $15 \mathrm{~N}-0 \mathrm{P}-15 \mathrm{~K}$ fertilizer at $336 \mathrm{~kg} / \mathrm{ha}$ and $10 \mathrm{~N}-10 \mathrm{P}-10 \mathrm{~K}$ fertilizer at $448 \mathrm{~kg} / \mathrm{ha}$, respectively, banded within the row. Raised beds were formed, sprayed with the herbicides terbacil (Sinbar $80 \mathrm{WP}$; Tessenderlo Kerley) at $0.22 \mathrm{~kg} / \mathrm{ha}$ on 7 April 2010 and S-metolachlor (Dual Magnum; Syngenta Crop Protection) at $35 \mathrm{ml} / \mathrm{ha}$ on $15 \mathrm{March}$ 2011, then covered with black polyethylene mulch. Liquid 8N-0P$8 \mathrm{~K}$ fertilizer was applied to the field throughout the season through the drip irrigation system (18). Standard applications of herbicides were made during the season based on weed occurrence, as well as preventative applications of fungicides effective against powdery mildew, gummy stem blight, and downy mildew and preventative applications of insecticides and miticides $(17,18)$.

Triploid watermelon Tri-X 313 was seeded in the greenhouse on 3 March 2010 and 7 March 2011. The same six rootstocks evaluated in the greenhouse were used in the field trial. Rootstocks were seeded in the greenhouse after seedless watermelon had emerged, as described above. Watermelon plants were grafted on 26 March 2010 and 29 March 2011 and transplanted on 15 April 2010 and 13 April 2011. Nongrafted and self-grafted Tri-X 313 were used as susceptible control treatments. Plots were arranged in randomized complete blocks replicated six times. Plots were each $12.1 \mathrm{~m}$ long with 12 plants in 2010 and 13.7 m long with 15 plants in 2011, and plants were spaced $0.9 \mathrm{~m}$ apart within rows. Plots were separated within rows by 3.0 and $4.6 \mathrm{~m}$ of nonplanted space in 2010 and 2011, respectively. The watermelon pollenizer 'SP5' (Syngenta Seeds) was transplanted between every fourth grafted plant to yield three pollenizer plants per plot. Disease incidence was determined by counting the number of plants with symptoms of wilted or dead vines and the number of dead plants on 26 and 29 April; 3, 6, 11, 14, 19, and 26 May; and 2 and 16 June 2010; and 21 and 26 April and 2, 9, 16, 23 and 31 May 2011. On 28 April or 7 May 2010, one symptomatic plant per plot was removed, and two pieces from the stem below the graft union and two pieces from the vine above the first true leaf of the scion were disinfested in $0.5 \%$ sodium hypochlorite for $1 \mathrm{~min}$, then cultured on Komada's agar medium. For nongrafted Tri-X 313, pieces of stem and vine were cut from approximately the same sites of the plants as on grafted plants. Marketable fruit were harvested and weighed three times weekly between 23 June and 7 July 2010 and five times weekly between 16 June and 13 July 2011.

Race identification. Fungal isolates recovered from grafted or nongrafted seedless Vanessa watermelon in 2006 were inoculated onto the differential cultivars Black Diamond, Charleston Gray, and Allsweet, which are susceptible to all races of $F$. oxysporum $\mathrm{f}$. sp. niveum, resistant to race 0 , and resistant to race 1 , respectively (45). Inoculum was produced as described previously for the greenhouse inoculation experiments, except that liquid Komada's medium was used (20). The differential cultivars were seeded in a 50:50 sand/perlite medium and grown for 14 days prior to inoculation, when the first true leaf was fully expanded. Seedlings were removed from the growing medium, and the roots were rinsed gently in tap water and dipped into a suspension of $10^{5}$ microconidia/ml. Seedlings were transplanted into Fafard 3B potting mix in 10-cm-diameter pots for each of four pots with four seedlings per pot and held in a greenhouse at approximately $24^{\circ} \mathrm{C}$ for 21 days. Each seedling was then rated as healthy or diseased, and the percentage of infected seedlings was calculated for each differential cultivar. Pieces of the hypocotyl of one symptomatic Allsweet seeding per pot were cultured on Komada's agar medium to confirm infection by $F$. oxysporum.

Statistical analysis. Data on recovery of $F$. oxysporum from plants in the greenhouse experiments with nongrafted rootstocks were analyzed using SAS PROC MIXED with experiment repetition, inoculation treatment, race, and cultivar as fixed effects, and replication within experiments as a random effect. Percent recov- 
ery was transformed with arcsine-square root before analysis. For analysis of percent recovery from both the top and base of each plant, 0 and $100 \%$ were replaced with $25 / n$ and $100-25 / n$, respectively, where $n=20$, the number of plants (38).

Data on recovery of $F$. oxysporum from plants in the greenhouse experiments with grafted rootstocks were analyzed using SAS PROC CATMOD for categorical data, which uses a $\chi^{2}$ statistic to determine treatment effects. The proportions of plants from which $F$. oxysporum was or was not recovered (a binary response) were transformed by calculating the logit, and the linear model parameters were then estimated using the maximum likelihood option. In order to get models to converge (i.e., arrive at a unique solution) that included zero values for some categories, observed proportions were replaced with a Bayes estimator calculated as $x=(c t+k / r) \times n /(n+k)$, where $x=$ the transformed proportion, $c t=$ count of plants with (or without) $F$. oxysporum, $r$ $=2$ (for a binary response), $k=$ a constant (which was set equal to $r$ ), and $n=$ total number of plants per treatment combination (37). Stepwise model reduction was done to improve the sensitivity of the analysis. When treatment effects were significant, contrast statements were written to compare treatment levels. Two-way interactions of inoculation and cultivar were examined by including nested-by-value effects in model statements to compare inoculation treatments within cultivars. Proportions were generated using the predict option to back-transform logit values. Categorical analysis of variance also was used to examine the proportions of pathogenic and nonpathogenic isolates recovered from plants inoculated in the greenhouse, and the proportions of plants from which $F$. oxysporum was recovered in the 2006 field experiment.

Disease and yield data from field experiments were analyzed with SAS PROC MIXED, with treatment as a fixed effect and block as a random effect. Before analysis, disease incidence percentages for the early season in 2010 and the early and late season in 2011 were transformed with arcsine of the square root to correct

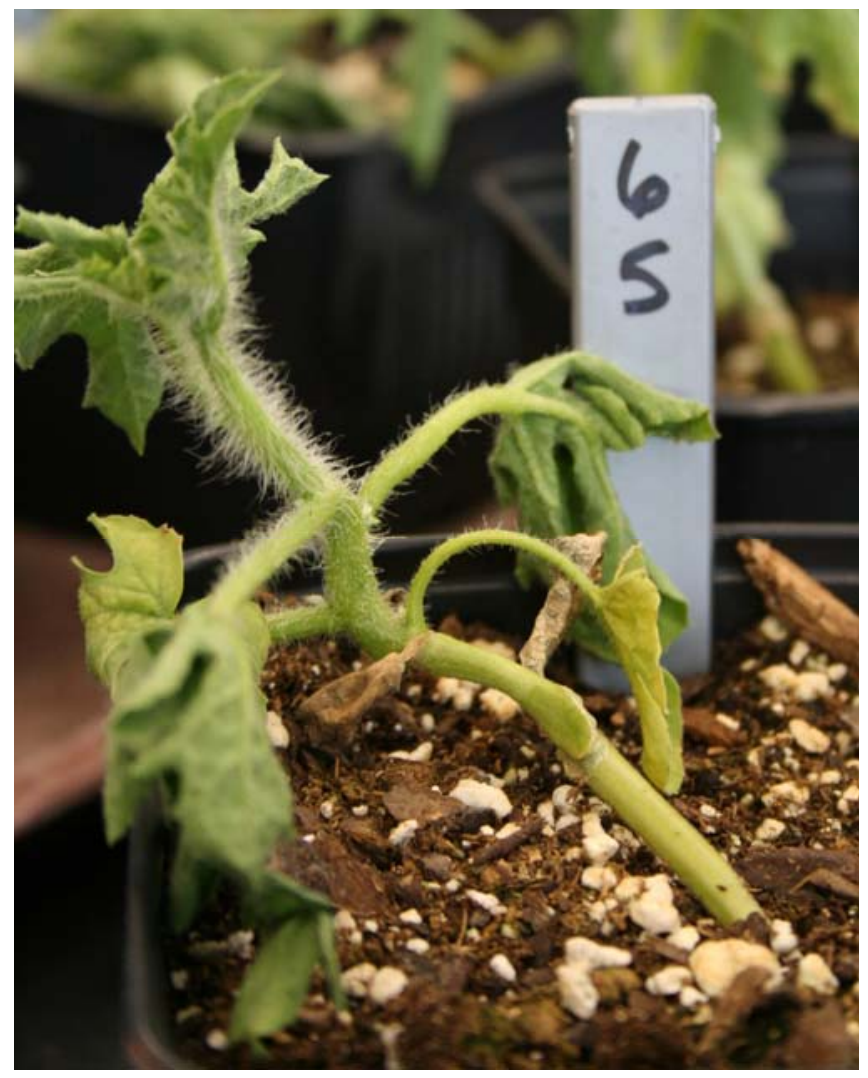

Fig. 1. Wilted Tri-X 313 seedless watermelon scion on wilted Ojakkyo citron rootstock that had been inoculated with Fusarium oxysporum f. sp. niveum in a greenhouse after grafting. for non-normality and inequality of variances among treatments. Back-transformed means are shown in the tables. When yield data from the two experiments were combined, year, treatment, and the year-treatment interaction were tested as fixed effects and blockyear as a random effect. Preplanned, single-degree-of-freedom contrasts were used to compare rootstock genera and to compare rootstocks with watermelon treatments.

\section{Results}

Disease development in greenhouse experiments. In the four experiments with nongrafted plants, all noninoculated control plants were symptomless (i.e., no plants wilted) and all inoculated bottlegourd and interspecific hybrid squash plants also were symptomless. Tri-X 313 had 65 to $100 \%$ symptomatic plants across the four experiments. Allsweet (resistant to race 1) was symptomless when inoculated with race 1 and had $70 \%$ symptomatic plants when inoculated with race 2 in experiment 1 . This cultivar was uncharacteristically $100 \%$ symptomless in experiment 2 when inoculated with race 2. Ojakkyo citron plants showed typical symptoms of wilting when inoculated with race 1 or race 2 in the first experiment (100\% of inoculated plants for each race), although there were no symptoms in the second experiment with race 2. F. oxysporum was recovered from the base of all symptomatic plants. The fungus was recovered from $100 \%$ of the tops of Tri-X 313 plants and from 86 to $100 \%$ of the tops of symptomatic Ojakkyo plants.

In the four experiments with grafted plants, all noninoculated control plants were symptomless. The nongrafted Tri-X 313 control had 40 to $80 \%$ symptomatic plants when inoculated with race 1 and $\geq 90 \%$ symptomatic plants when inoculated with race 2 . Nongrafted Allsweet watermelon was symptomless when inoculated with race 1 and had 15 to $60 \%$ symptomatic plants when inoculated with race 2 . Self-grafted Tri-X 313 plants had 55 and $75 \%$ wilt incidence when inoculated with race 1 and race 2 , respectively. Tri-X 313 scions grafted onto Ojakkyo plants showed typical symptoms of wilting when inoculated with race $1(60 \%$ of the plants) and race 2 (20 to $30 \%$ of the plants) (Fig. 1). F. oxysporum was recovered from $100 \%$ of the rootstock portions (bases) of symptomatic plants. The species also was recovered from $100 \%$ of the scions on all symptomatic plants grafted onto Ojakkyo and from nongrafted Tri-X 313 and Allsweet watermelon. However, recovery from the scions of symptomatic, self-grafted Tri-X 313 was $73 \%$ for race 1 inoculations and $80 \%$ for race 2 inoculations. In addition, one scion grafted onto 'Strong Tosa' showed wilt symptoms when inoculated with race 1 in experiment 1 , and two scions grafted onto Macis showed wilt symptoms when inoculated with race 2 in experiment 2. F. oxysporum was isolated from the Strong Tosa rootstock and from one of the two Macis rootstocks but was not isolated from the three scions.

Recovery of $F$. oxysporum from noninoculated plants. In addition to recovery from symptomatic plants, $F$. oxysporum was recovered from the bases of 0 to $40 \%$ of the noninoculated control plants in six of the eight experiments. In the experiments with nongrafted plants inoculated with race 1 , percent recovery of $F$. oxysporum was not significantly $>0$ based on $t$ tests $(P \geq 0.25$; Fig. $2 A)$. In the experiments with nongrafted plants inoculated with race 2 , there was an inoculation-experiment interaction $(P=$ 0.002). Percent recovery from noninoculated plants of Macis, 'WMXP 3945', 'Shintosa Camel', Strong Tosa, and Tri-X 313 was significantly $>0$ in the first experiment (Fig. 2B) and percent recovery from Ojakkyo was significantly $>0$ in the second experiment $(t$ tests, $P<0.05$; Fig. 2C).

With grafted plants inoculated with race 1 , percent recovery of $F$. oxysporum from bases of the rootstocks or the nongrafted watermelon control plants was not significantly $>0$ for any cultivar in experiment 1 (single-degree-of-freedom contrasts, $P \geq 0.34$; Fig. $3 \mathrm{~A})$. In experiment 1 with race 2 and grafted plants, percent recovery was significantly $>0$ for Emphasis and WMXP 3945 bottlegourds and for Ojakkyo citron but not for the other cultivars $(P \leq$ 0.04; Fig. 3C). In experiment 2 for each race, percent recovery of 
F. oxysporum from the bases of rootstocks was not significantly $>0$ for any cultivars (Fig. 3B and D).

F. oxysporum was recovered from the tops of 2 of $640(0.3 \%)$ noninoculated, nongrafted plants and 0 to 3 (mean of $2.4 \%$ ) inoculated, nongrafted plants when the fungus was not recovered from the bottom of the same plant. There was no significant difference among cultivars for recovery from only the top of inoculated plants $(P=0.81)$. Similarly, in the experiments with grafted plants, $F$. oxysporum was recovered from 0 to 2 scions of noninoculated or inoculated plants of each cultivar summed across the four experiments. Based on categorical ANOVA, percent recovery from scions of plants did not differ between inoculated and noninoculated grafted plants or among cultivars $\left(\chi^{2}=0.0, P=1.00\right)$.

Of the 73 isolates recovered from the bases or tops of noninoculated plants, 72 were nonpathogenic when tested on the Fusarium wilt-susceptible Sugar Baby (Table 2). The single pathogenic isolate was recovered from the base of a symptomless, grafted Ojakkyo plant in the first experiment with race 2 . In all pathogenicity tests, the race 1 and race 2 isolates used in this study and included as positive control treatments were pathogenic, whereas the noninoculated Sugar Baby seedlings remained symptomless.

Recovery of $\boldsymbol{F}$. oxysporum from bases of inoculated plants in greenhouse experiments. There was a race-cultivar interaction $(P$ $<0.0001$ ) for the percent recovery of $F$. oxysporum from the bases of inoculated, nongrafted plants. However, for both races, percent recovery from inoculated plants was greater than from noninoculated plants for each cultivar $(P<0.02$ for race 1 and $P \leq 0.001$ for race 2; Fig. 2). Thus, F. oxysporum f. sp. niveum races 1 and 2 colonized the bases of inoculated, nongrafted plants. Percent recovery from bases of Tri-X 313, Ojakkyo, and Allsweet plants inoculated with race 1 was greater than from all bottlegourd and interspecific hybrid squash cultivars, which did not differ from each other $(P<0.01$; Fig. $2 \mathrm{~A})$. When nongrafted plants were inoculated with race 2, percent recovery of $F$. oxysporum was 79 to $100 \%$ (Fig. 2B and C). Frequency of recovery did not differ among cultivars $(P=0.69$ and $P=0.29$ for cultivar effects in experiments 1 and 2 , respectively).

When grafted plants were inoculated with $F$. oxysporum f. sp. niveum, there was a race-experiment interaction $(P<0.02)$. In both experiments with race 1 and in experiment 2 with race 2 , percent recovery of $F$. oxysporum was greater from inoculated Ojakkyo as well as nongrafted and self-grafted Tri-X 313 plants than from the corresponding noninoculated cultivars $(P<0.01)$, whereas percent recovery did not differ between inoculated and noninoculated plants of bottlegourd and interspecific hybrid squash (Fig. 3A, B, and D). In experiment 1 with race 2 , percent recovery differed between inoculated and noninoculated treatments for nongrafted Tri-X 313 and Strong Tosa $(P \leq 0.03)$ but not for the other cultivars (Fig. 3C).

With both races, $F$. oxysporum was isolated more frequently from the bases of inoculated, nongrafted (control) plants of Tri-X 313 and grafted Ojakkyo than from inoculated, grafted bottlegourd and interspecific hybrid squash rootstocks $(P \leq 0.05)$ (Fig. 3). The only exception was with race 2 in experiment 1 , when frequency of recovery from Shintosa Camel plants was not significantly different from that of Tri-X 313 ( $P=0.09$; Fig. 3C). In the two experiments that included self-grafted Tri-X 313 as a grafting control treatment, recovery was as great from self-grafted plants as from nongrafted plants of Tri-X 313 (Fig. 3B and D).

Recovery of $F$. oxysporum from the top and base of inoculated plants. As reported above, $F$. oxysporum was recovered infrequently from the tops of inoculated plants from which the fungus was not recovered from the base of the same plant. Thus, the percentage of plants from which $F$. oxysporum was recovered from both the base and the top of the same plant was considered the most appropriate measure of colonization. F. oxysporum was not recovered from both the top and bottom of any noninoculated, nongrafted plants in any of the four experiments. With race 1 inoculation, percent recovery was greater from inoculated plants than from noninoculated plants of Allsweet, Macis, Shintosa Camel,
Ojakkyo, and Tri-X $313(P \leq 0.01)$. With race 2 inoculation, percent recovery was greater from inoculated plants than noninoculated plants of Allsweet, Ojakkyo, Strong Tosa, and Tri-X 313 in the first experiment, and for all cultivars except Allsweet in the second experiment.

The frequency of recovery of $F$. oxysporum from the top and base of nongrafted plants inoculated with each race was greater for

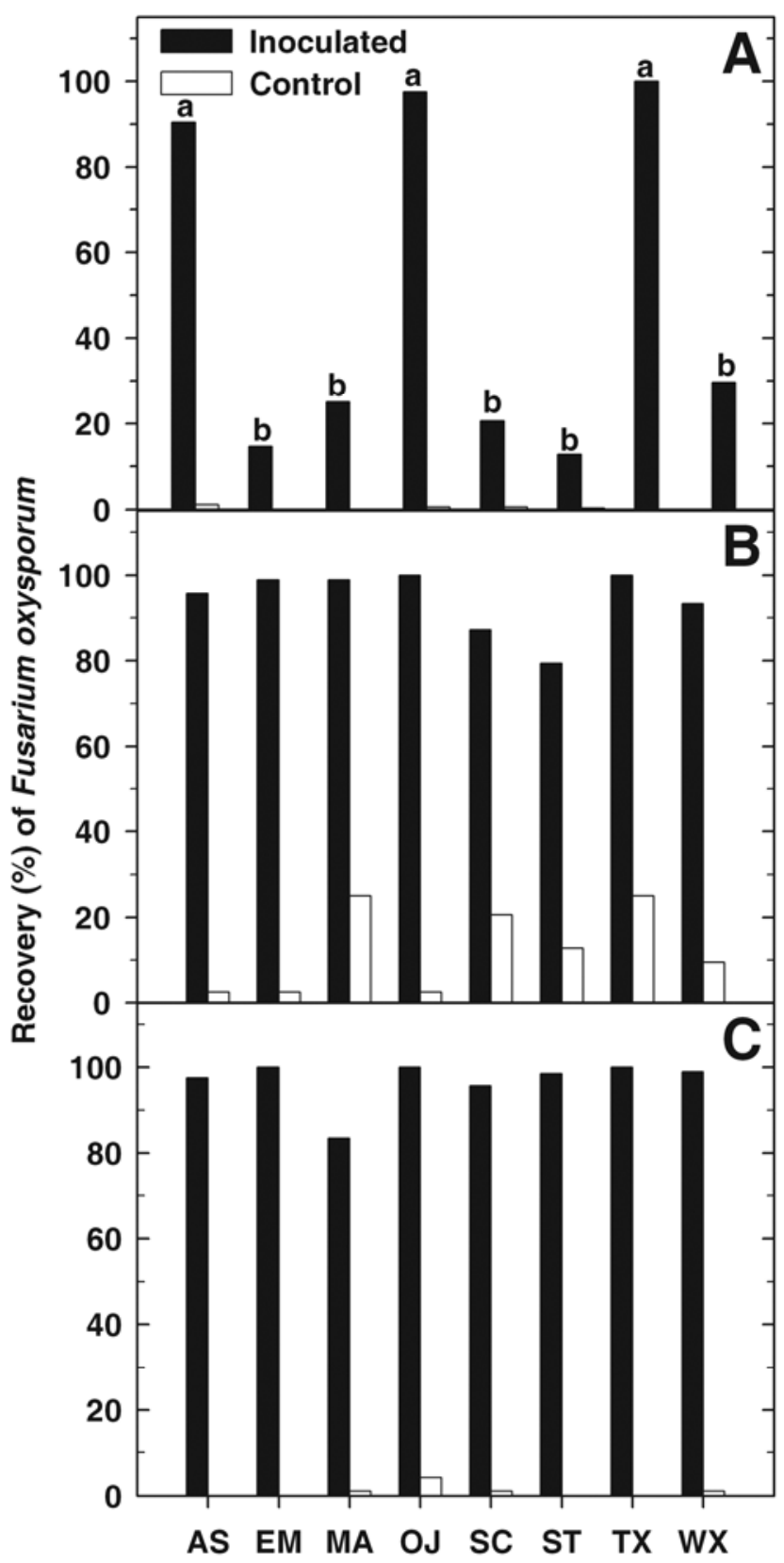

Fig. 2. Percent recovery of Fusarium oxysporum from the base of nongrafted plants that were not inoculated or were inoculated with $F$. oxysporum $f$. sp. niveum in a greenhouse. Each mean is based on 20 plants arranged as four plants in each of five replicate pots in each of two experiments. Cultivar abbreviations are shown in Table 1. Percent recovery from inoculated plants was greater than from noninoculated plants for each cultivar $(P<0.02)$. A, Inoculation with race 1 of $F$. oxysporum $\mathrm{f}$. sp. niveum, for which there was no significant difference between the two experiments. Means for inoculated cultivars with the same letter were not significantly different based on $t$ tests $(P<0.0001)$. Means for noninoculated cultivars did not differ significantly. With race 2 of the pathogen, results of $\mathbf{B}$, experiment 1 and $\mathbf{C}$, experiment 2 differed because there was an inoculationexperiment interaction $(P=0.002)$, with greater recovery of $F$. oxysporum from noninoculated plants in experiment 1 than in experiment 2. In both experiments with race 2 ( $B$ and $C$ ), percent recovery of $F$. oxysporum from plants did not differ among cultivars within inoculation treatments. Refer to the main text for details of how $F$. oxysporum was recovered from plants. 
the susceptible watermelon control treatment than for the three bottlegourd and two interspecific hybrid squash rootstocks $(P \leq$ 0.01 ; Fig. 4). Note that the susceptible watermelon control was Tri$\mathrm{X} 313$ in the race 1 experiments and the second race 2 experiment, whereas Black Diamond served this purpose in the first experiment with race 2 . There was a significant interaction among race, cultivar, and experiment, primarily due to different responses of Ojakkyo and Allsweet. With race 1 inoculation, frequency of recovery of $F$. oxysporum from Ojakkyo was less than from Tri-X 313 ( $P=$ 0.01 ; Fig. 4A). With race 2 inoculation, recovery of $F$. oxysporum from Ojakkyo did not differ from that of Black Diamond in experiment $1(P=0.055)$ but was less than recovery from Tri-X 313 in experiment $2(P<0.0001)$ (Fig. 4B). In both race 1 experiments and in the first experiment with race 2 , recovery from Ojakkyo was greater than recovery from the other five rootstock cultivars and from Allsweet (Fig. 4). In the second experiment with race 2, there were no differences in recovery of $F$. oxysporum between Ojakkyo and the other cultivars (Fig. 4B). With race 1 inoculation, the frequency of recovery from Allsweet, which is resistant to race 1, did not differ from recovery from the bottlegourd and interspecific hybrid squash cultivars (Fig. 4A). However, recovery of $F$. ox- ysporum from Allsweet differed between the two experiments with the race 2 isolate of $F$. oxysporum $\mathrm{f}$. sp. niveum (Fig. 4B). In the first experiment, recovery from Allsweet was greater than recovery from the bottlegourd and interspecific hybrid squash cultivars, except Strong Tosa $(P \leq 0.006)$. In the second experiment with race 2, percent recovery of $F$. oxysporum from Allsweet did not differ from that of any rootstock cultivars.

Percent recovery of F. oxysporum from both the scion and rootstock portions of grafted plants did not differ between race 1 and race 2 isolates of the pathogen $(P=0.23)$. However, there was a significant inoculation-cultivar interaction $(P<0.0001)$. $F$. oxysporum was recovered more frequently from inoculated Allsweet, Ojakkyo, self-grafted Tri-X 313, and nongrafted Tri-X 313 than from the corresponding noninoculated cultivars $(P \leq 0.0003$; Fig. $5)$. Percent recovery was low for bottlegourd and interspecific hybrid squash rootstocks, and inoculated and noninoculated plants did not differ significantly for these five cultivars in terms of recovery of $F$. oxysporum $(P \geq 0.49)$.

A separate analysis was done with data only from the inoculated, grafted plants because of the inoculation-cultivar interaction. Frequency of recovery was consistent between experiments and

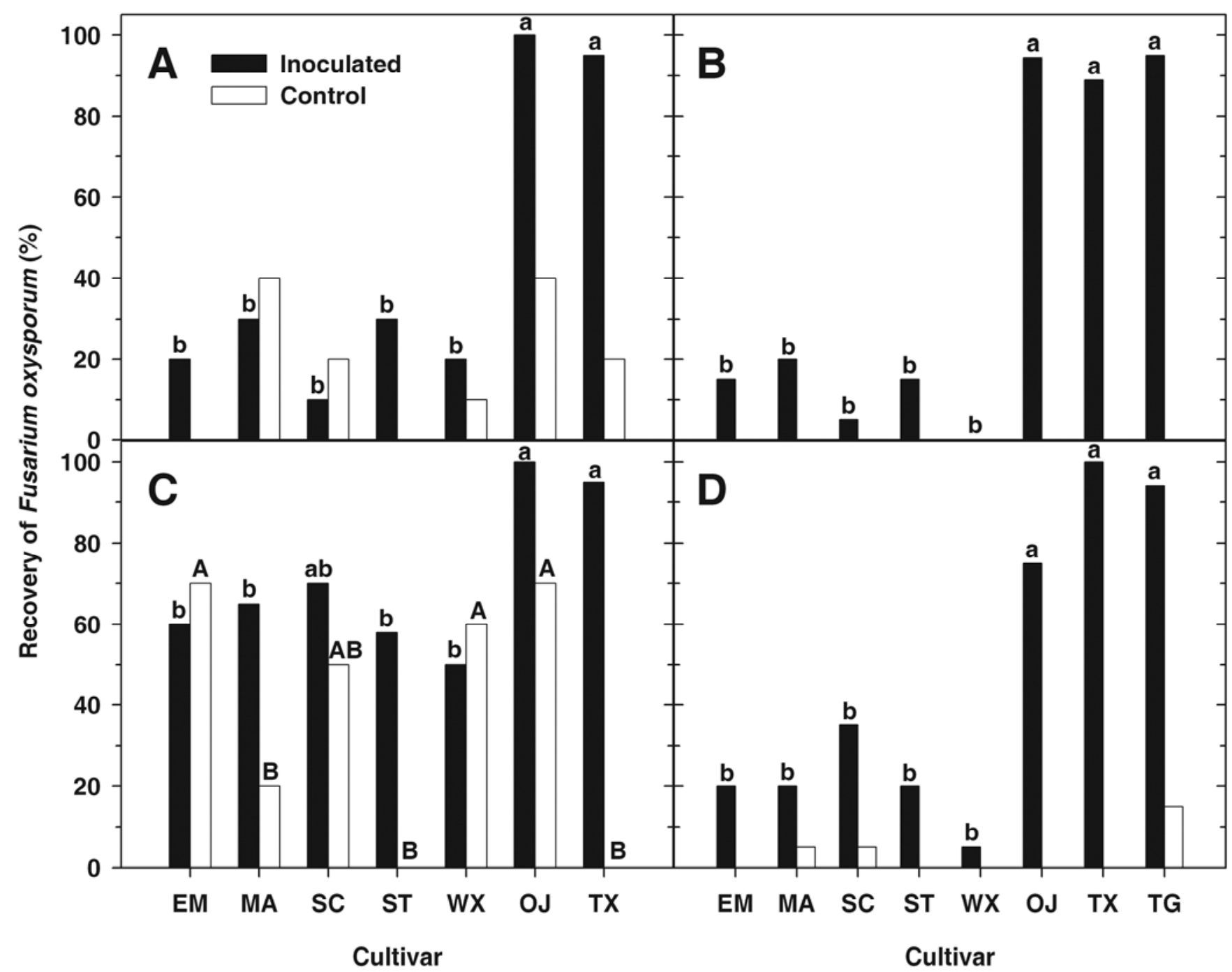

Fig. 3. Percent recovery of Fusarium oxysporum from the base of grafted plants that were not inoculated or were inoculated with $F$. oxysporum f. sp. niveum in a greenhouse. Missing white bars indicate no recovery. Cultivar abbreviations are shown in Table 1; TG = Tri-X 313 self-grafted control treatment. Percent recovery did not differ among noninoculated cultivars without letters shown. A, In experiment 1 with race 1 of $F$. oxysporum f. sp. niveum, percent recovery from inoculated cultivars with the same letter did not differ significantly based on $t$ tests $(P \leq 0.008)$. B, In experiment 2 with race 1 , percent recovery from inoculated cultivars with the same letter did not differ significantly based on $t$ tests, $(P \leq 0.005)$. C, In experiment 1 with race 2, percent recovery from inoculated cultivars with the same lowercase letter did not differ significantly based on $t$ tests $(P \leq 0.05)$. Percent recovery from noninoculated cultivars with the same uppercase letter did not differ significantly based on $t$ tests $(P \leq 0.05)$. D, In experiment 2 with race 2, percent recovery of $F$. oxysporum from inoculated cultivars with the same letter did not differ significantly based on $t$ tests $(P \leq 0.002)$. Refer to the main text for details on the isolation method used to recover $F$. oxysporum. 
between races, because there were no significant main effects or interactions between experiment and race main effects $(P>0.18)$. Percent recovery from scions (or tops) and rootstocks (or bases of plants) of nongrafted Tri-X 313, self-grafted Tri-X 313, nongrafted Allsweet, and grafted Ojakkyo was significantly greater than from the five bottlegourd and interspecific hybrid squash rootstocks $(P \leq$ 0.01; Fig. 5). Percent recovery from Tri-X 313 and Ojakkyo did not differ, and recovery from both was greater than recovery from Allsweet $(P \leq 0.01)$. Percent recovery from self-grafted Tri-X 313 was greater than from bottlegourd and interspecific hybrid squash rootstocks but less than from nongrafted Tri-X $313(P \leq 0.01)$.

In all, 6 of 7 isolates recovered from the tops of nongrafted, inoculated plants and 9 of 14 isolates recovered from the scions of grafted, inoculated plants were pathogenic on watermelon (i.e., were identified as $F$. oxysporum f. sp. niveum); 2 of 9 isolates recovered from the rootstocks of grafted, inoculated plants were pathogenic (Table 2). All four isolates recovered from the stem above the cotyledons on inoculated, nongrafted Tri-X 313 and Allsweet plants were pathogenic. In a categorical ANOVA, the proportion of pathogenic isolates among all recovered isolates was greater from inoculated than noninoculated plants $(P=0.001)$ and greater from the tops than the bases of plants $(P=0.02)$. The predicted probability of recovering a pathogenic isolate from the base of noninoculated plants was $0.03 \pm 0.02$ (mean \pm standard error), whereas the predicted probability of recovering a pathogenic isolate from inoculated plants was $0.28 \pm 0.13$ from the base and 0.69 \pm 0.10 from the top.

Field experiments. In the 2010 and 2011 field experiments, symptoms of Fusarium wilt appeared by 8 days after transplanting. Disease progression differed between years; therefore, data from each year were analyzed separately. In 2010, when inoculum was added to the transplanting holes, $F$. oxysporum $\mathrm{f}$. sp. niveum readily infected the roots of young plants. Disease progressed rapidly for the first 3 weeks after transplanting and then reached a plateau for the rest of the season (Fig. 6). Self-grafted Tri-X 313 had the greatest incidence of Fusarium wilt for the entire 2010 growing season, and plants grafted onto Ojakkyo citron had the second greatest incidence (Fig. 6). In 2011, plants grafted onto Ojakkyo had the greatest disease incidence 19 days after transplanting but nongrafted Tri-X 313 had the greatest incidence for the rest of the growing season (Table 3; Fig. 6). In both years, plants grafted onto Ojakkyo showed symptoms within 4 weeks after transplanting, and wilt incidence increased $<5 \%$ after that time (Fig. 6).

At 48 days after transplanting, $>50 \%$ of the self-grafted Tri-X 313 plants and plants grafted on Ojakkyo showed wilt symptoms in 2010, compared with $45.8 \%$ wilt incidence for Tri-X 313 nongrafted plants; whereas, in 2011, only $21.9 \%$ of Ojakkyo grafted plants had wilt symptoms and $25.6 \%$ of self-grafted Tri-X 313 plants were wilting, compared with $>50 \%$ of the nongrafted Tri-X 313 plants which were wilted (Fig. 6). In both years, more Tri-X 313 plants (averaged across both control treatments) showed

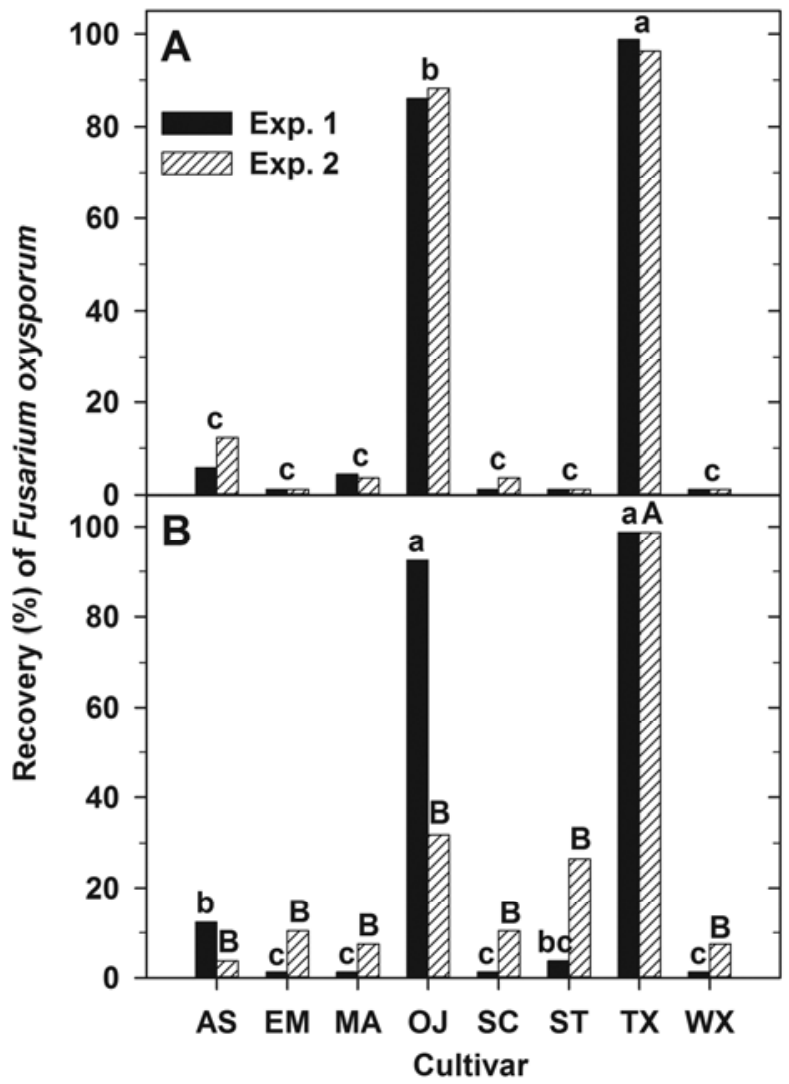

Fig. 4. Percent recovery of Fusarium oxysporum from both the base and the top of nongrafted plants 3 weeks after inoculation with race 1 or race 2 of $F$. oxysporum $f$. $\mathrm{sp}$. niveum in four greenhouse experiments. Cultivar abbreviations are shown in Table 1. Each mean is based on 20 plants arranged as four plants in each of five replicate pots. Values are back-transformed from arcsine-square roots, where a value of 1.25 is equivalent to 0 of 20 plants. A, For race 1 inoculations across the two experiments, cultivars with the same letter are not significantly different based on $t$ tests $(P \leq 0.001)$. B, For race 2, Black Diamond was substituted for Tri-X 313 in experiment 1. Cultivars with the same letter are not significantly different based on $t$ tests $(P \leq 0.006$ for experiment 1 , designated with lowercase letters, and $P<$ 0.0001 for experiment 2, designated with uppercase letters). Refer to the main text for details of how $F$. oxysporum was recovered from plants.

Table 2. Pathogenicity to Sugar Baby watermelon of isolates of Fusarium oxysporum that were recovered from noninoculated plants or plants inoculated with $F$. oxysporum f. sp. niveum in eight greenhouse experiments ${ }^{\mathrm{x}}$

\begin{tabular}{|c|c|c|c|c|c|c|c|}
\hline \multirow[b]{2}{*}{ Grafting } & \multirow[b]{2}{*}{ Race } & \multirow[b]{2}{*}{ Experiment } & \multirow[b]{2}{*}{ Inoculation } & \multicolumn{2}{|c|}{ Recovered from top or scion of plant ${ }^{y}$} & \multicolumn{2}{|c|}{ Recovered from base of plant ${ }^{z}$} \\
\hline & & & & Number of isolates & Number pathogenic & Number of isolates & Number pathogenic \\
\hline Nongrafted & 1 & 1 & Control & n.d. & n.d. & 11 & 0 \\
\hline Nongrafted & 2 & 1 & Control & 1 & 0 & 23 & 0 \\
\hline Nongrafted & 2 & 2 & Control & n.d. & n.d. & 3 & 0 \\
\hline Grafted & 1 & 1 & Control & 1 & 0 & 8 & 0 \\
\hline Grafted & 2 & 1 & Control & 3 & 0 & 22 & 1 \\
\hline Grafted & 2 & 2 & Control & 1 & 0 & n.d. & n.d. \\
\hline Nongrafted & 1 & 2 & Inoculated & 4 & 3 & n.d. & n.d. \\
\hline Nongrafted & 2 & 2 & Inoculated & 3 & 3 & n.d. & n.d. \\
\hline Grafted & 1 & 1 & Inoculated & 1 & 0 & 3 & 2 \\
\hline Grafted & 1 & 2 & Inoculated & 6 & 6 & n.d. & n.d. \\
\hline Grafted & 2 & 1 & Inoculated & 5 & 2 & 6 & 0 \\
\hline Grafted & 2 & 2 & Inoculated & 2 & 1 & n.d. & n.d. \\
\hline
\end{tabular}

${ }^{\mathrm{x}}$ Pathogenic isolates caused wilting or death of four or more of six watermelon seedlings 14 days after seeds were inoculated with a microconidial suspension of the F. oxysporum isolate when sown into potting soil; n.d. = not done.

${ }^{y}$ Isolates were obtained from surface-disinfested pieces of the stem between the first and second true leaf of nongrafted plants or the scion of grafted plants, as detailed in the main text.

${ }^{\mathrm{z}}$ Isolates were obtained from surface-disinfested pieces cut approximately $1 \mathrm{~cm}$ above the soil line from the stem of nongrafted plants or the rootstock portion of grafted plants, as detailed in the main text. 
symptoms than scions grafted onto bottlegourd or interspecific hybrid squash rootstocks (single-degree-of-freedom contrasts, $P<$ 0.05 and $P<0.0001$ in 2010 and 2011, respectively). Disease incidence did not differ between self-grafted Tri-X 313 and Ojakkyo (Table 3). In both years, there were no differences between bottlegourd and interspecific hybrid squash rootstocks and no differences among cultivars within each rootstock genus. In 2010, selfgrafted Tri-X 313 plants had a greater late-season disease incidence than all other treatments except Ojakkyo citron $(P \leq 0.05$;

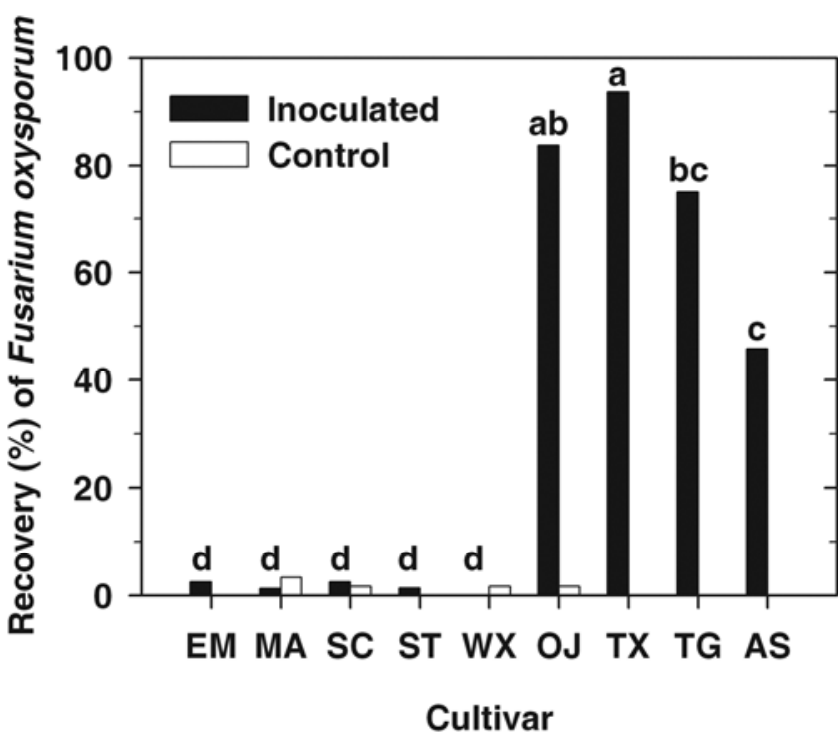

Fig. 5. Percent recovery of Fusarium oxysporum from both the base of the rootstock portion and the Tri-X 313 scion on grafted plants 3 weeks after inoculation with race 1 or race 2 of $F$. oxysporum f. sp. niveum in a greenhouse. Cultivar abbreviations are shown in Table 1; TG $=$ Tri-X 313 self-grafted control treatment. Cultivars were grafted with seedless watermelon Tri-X 313 , except the nongrafted Tri-X 313 (TX) and nongrafted Allsweet (AS) control treatments. Each value is a mean across four experiments, two each with race 1 and race 2 isolates, because there were no significant interactions among cultivar, race, or experiment effects in the analysis. Percent recovery from inoculated cultivars with the same letter did not differ significantly based on $\chi^{2}$ tests $(P \leq 0.01)$. Percent recovery did not differ among noninoculated cultivars. Refer to the main text for details of how $F$. oxysporum was recovered from plants.
Table 3). In addition, more grafted Ojakkyo citron plants showed symptoms of wilt than grafted Emphasis plants. In 2011, nongrafted Tri-X 313 had more wilted plants late in the season than any other treatment except self-grafted Tri-X 313.

For weight, number, and average size of fruit, there were significant effects of year $(P<0.0001$ for each measurement $)$ and treatment $(P<0.0001, P=0.0070$, and $P=0.0131$, respectively) but no significant interactions $(P>0.81)$; therefore, yield data were combined. Yields were almost twice as great in 2011 as in 2010. Mean weight of marketable fruit harvested was 29.8 and $56.8 \mathrm{Mg} / \mathrm{ha}$ in 2010 and 2011, respectively, and mean number of fruit per hectare was 3,984 and 8,183 in 2010 and 2011, respectively. In general, grafting watermelon onto cucurbit rootstocks increased weight and number of fruit (single-degree-of-freedom contrasts between watermelon control treatments and cucurbit rootstocks: $P=0.0002$ for weight and $P=0.007$ for number of fruit). All three grafted bottlegourd (Lagenaria spp.) cultivars produced a greater marketable fruit weight than nongrafted and self-grafted Tri-X 313 (Table 4). Tri-X 313 grafted onto interspecific hybrid squash Strong Tosa also yielded more fruit by weight than the Tri-X 313 control treatments. Weight of fruit produced by grafted Ojakkyo plants did not differ significantly from that of nongrafted and self-grafted Tri-X 313 plants. Watermelon grafted onto Emphasis produced a greater number of fruit than watermelon grafted onto Shintosa Camel, Ojakkyo, and the watermelon control treatments (Table 4). When mean fruit numbers across rootstock genera were compared with single-degree-of-freedom contrasts, watermelon grafted onto bottlegourd rootstocks produced more fruit per hectare $(n=6,949)$ than watermelon grafted onto Ojakkyo citron $(n=5,555, P=0.014)$ or interspecific hybrid squash rootstocks $(n=5,865, P=0.015)$.

Watermelon grafted onto bottlegourd, interspecific hybrid squash, and citron rootstocks produced larger fruit than the two watermelon control treatments (single-degree-of-freedom contrasts, $P \leq 0.01)$. Watermelon grafted onto citron also yielded larger fruit than watermelon grafted onto bottlegourd (Table 4). The size of fruit produced on interspecific hybrid squash rootstocks was intermediate to the size of fruit produced on citron and bottlegourd rootstocks. Watermelon grafted onto bottlegourd and interspecific hybrid squash rootstocks produced fruit between 0.3 and $0.7 \mathrm{~kg}$ larger than the ideal watermelon fruit size of $6.8 \mathrm{~kg}$, and fruit produced on the citron rootstock was $1.0 \mathrm{~kg}$ larger (34).

Recovery of $F$. oxysporum and $F$. oxysporum f. sp. niveum from field-grown, grafted plants. In all, 12 isolates of $F$. $o x$ -

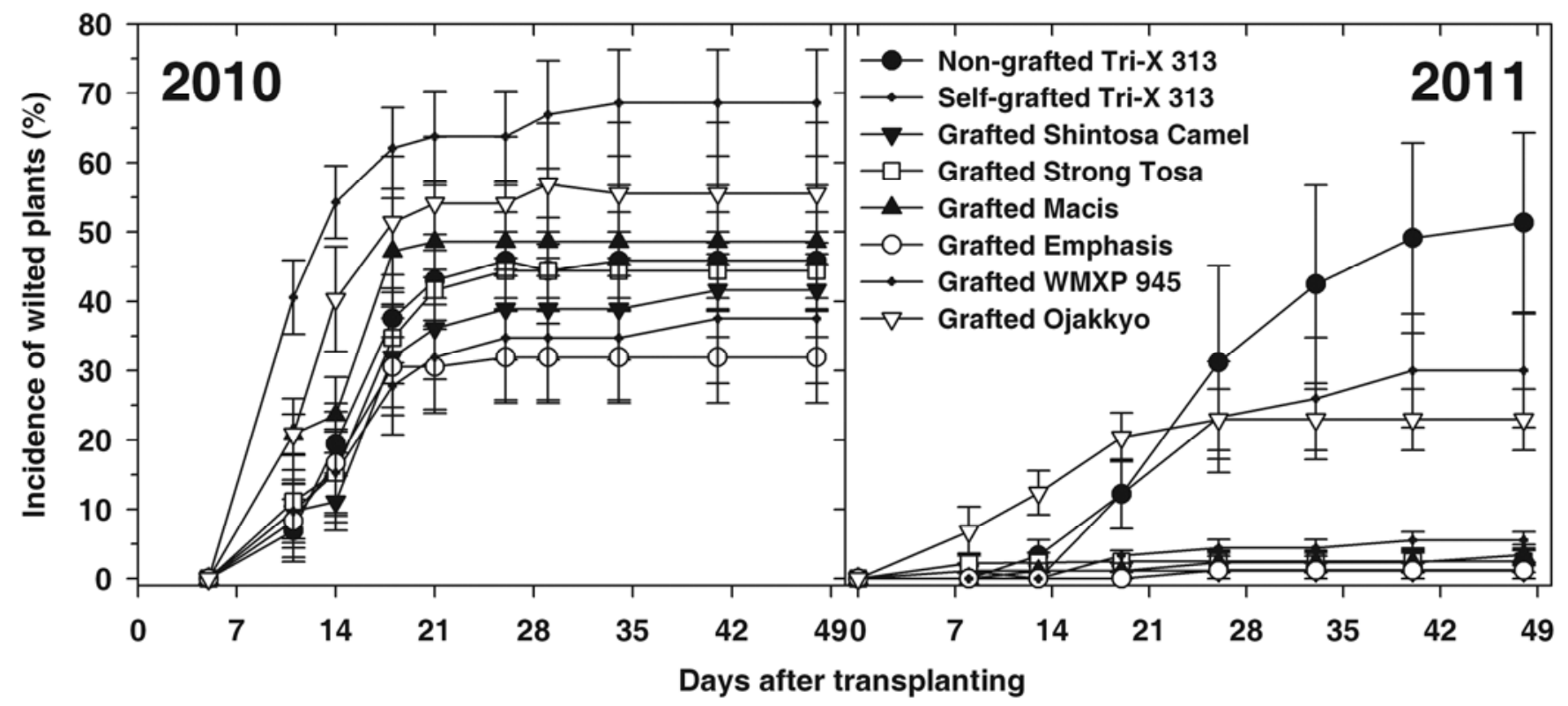

Fig. 6. Progression of Fusarium wilt symptoms on seedless Tri-X 313 watermelon grafted onto each of six rootstocks, self-grafted, or not grafted and planted in a field in Charleston, SC infested with a mixture of races 1 and 2 of Fusarium oxysporum f. sp. niveum in spring 2010 and 2011 . The legend shows rootstock cultivar names. Refer to Table 1 for details of each cultivar. Each data point is the mean and standard error of six observations. 
ysporum recovered in 2006 from grafted plants (10 isolates) or from nongrafted control plants ( 2 isolates) were tested for pathogenicity on three differential cultivars to determine whether the isolates were $F$. oxysporum $\mathrm{f}$. sp. niveum and, if so, which races. In total, 5 of the 10 isolates from scions of grafted plants and 1 of the 2 isolates from vines of nongrafted plants were $F$. oxysporum isolates that were not pathogenic on watermelon, because they caused no symptoms on any of the cultivars. The remaining five isolates from grafted plants were race 1 and the remaining isolate from the nongrafted plant was race 2 . The known isolate of race 2 included as a control isolate caused $\geq 75 \%$ wilt incidence on all three cultivars. F. oxysporum was recovered from all symptomatic Allsweet seedlings.

In $2010, F$. oxysporum was recovered from 17 to $100 \%$ of the symptomatic plants sampled in the field (Table 5). Recovery from nongrafted Tri-X 313 was $100 \%$ from both the top and base of the plants. Recovery did not differ significantly among cultivars $\left(\chi^{2}, P\right.$ $=0.31)$ or between the top and base of plants $\left(\chi^{2}, P=0.07\right)$. Across the eight grafting treatments, 23 and 34 of the 35 plants that were infected yielded $F$. oxysporum from the top or scion and from the base, respectively. Only one plant, a grafted Strong Tosa plant, yielded $F$. oxysporum only from the scion and not from the base of the rootstock. The forma specialis and race of $F$. oxysporum isolates collected in 2010 were not determined.

\section{Discussion}

The susceptible watermelon and citron cultivars used in this study showed typical symptoms of wilting when inoculated with two races of $F$. oxysporum $\mathrm{f}$. sp. niveum in a greenhouse. $F$. oxysporum was reisolated from 87 to $100 \%$ of the top portions and from $100 \%$ of the bases of the wilted, nongrafted, or grafted susceptible cultivars. However, the resistant bottlegourd and interspecific hybrid squash cultivars did not display symptoms even when the plants were infected by $F$. oxysporum f. sp. niveum in some experiments or replications. The five cultivars of bottlegourd and interspecific hybrid squash evaluated fit the definition of "asymptomatic hosts" recently proposed by Malcolm et al. (28), because they were infected by $F$. oxysporum f. sp. niveum but did not show disease symptoms. Asymptomatic infection of various plant hosts is common with $F$. oxysporum (23). Thus, infection cannot be used as the sole criterion for evaluating resistance of rootstock cultivars.

F. oxysporum infects host roots through unsuberized root tips (6). The distribution of $F$. oxysporum in planta was illustrated recently by use of colorimetric reagents that reacted with enzymes produced by the pathogen (5). When $F$. oxysporum f. sp. conglutinans infected roots of susceptible mutants of Arabidopsis, the fungus rapidly progressed to the vascular cylinder. Resistance to wilt was expressed as reduced root tip colonization or as a restriction of pathogen growth into the vascular cylinder (5). Because $F$. oxysporum f. sp. niveum was recovered from the stem bases on rootstock cultivars in the current study, the fungus clearly had progressed into the plant vascular system beyond the roots. Resistance of bottlegourd and interspecific hybrid squash to $F$. oxysporum $\mathrm{f}$. sp. niveum may involve mechanisms other than restriction of vascular tissue colonization, such as formation of tyloses that block or restrict movement of $F$. oxysporum after the fungus has entered the vascular cylinder $(6,24)$. Alternatively, it is possible that infection of the rootstock could trigger a resistant reaction in the scion (10). For example, Kuniyasu and Takeuchi (24) observed tyloses that had formed in a watermelon scion in response to infection of a bottlegourd rootstock by F. oxysporum f. sp. lagenariae.

Cucurbit rootstocks and watermelon can be infected by nonpathogenic $F$. oxysporum. Both noninoculated and inoculated nongrafted and grafted rootstock and watermelon plants were colonized by nonpathogenic F. oxysporum in this study. Similarly, $49 \%$ of 153 isolates of $F$. oxysporum recovered from surface-disinfested watermelon plants with symptoms of Fusarium wilt in Maryland and Delaware and $74 \%$ of isolates recovered from surface-disinfested watermelon seed in Tunisia were nonpathogenic on watermelon $(9,45)$. Because $F$. oxysporum was recovered from one sample of the brand of potting soil used in the greenhouse experiments in this study (A. P. Keinath, unpublished data), the potting soil likely was a source of the nonpathogenic $F$. oxysporum recovered from greenhouse plants. Recovery of $F$. oxysporum from all inoculated watermelon plants and from most inoculated rootstocks was greater than from noninoculated plants, which means that colonization of plants by $F$. oxysporum $\mathrm{f}$. sp. niveum was greater than by other $F$. oxysporum isolates present in the potting soil. Roots were exposed to $10^{6}$ conidia/ml when dipped in the conidial suspension of $F$. oxysporum $\mathrm{f}$. sp. niveum used to inoculate plants before the roots were exposed to $F$. oxysporum at $30 \mathrm{CFU} / \mathrm{g}$, present naturally in the potting soil (data not shown). Thus, even though isolates of $F$. oxysporum not pathogenic on watermelon have been shown to induce systemic resistance to Fusarium wilt in watermelon, the much greater inoculum density and prior exposure to the pathogen in the experiments in this study likely overcame any beneficial effects of root infection by other $F$. oxysporum isolates from the potting medium (25). It is possible that some of the nonpathogenic isolates of $F$. oxysporum recovered from noninoculated plants in the greenhouse experiments would not have been isolated if a longer root disinfestation treatment had been used. F. oxysporum $\mathrm{f}$. sp. niveum is relatively insensitive to sodium hypochlorite; inside watermelon stems, the fungus can survive up to $5 \mathrm{~min}$ in a $0.5 \%$ sodium hypochlorite solution (21).

With a few minor exceptions, colonization of plants inoculated with $F$. oxysporum f. sp. niveum in the greenhouse experiments fit

Table 3. Incidence of Fusarium wilt on seedless watermelon Tri-X 313 that was grafted onto six cucurbit rootstocks, self-grafted, or not grafted and planted into a field infested with Fusarium oxysporum f. sp. niveum races 1 and 2 in 2010 and 2011 in Charleston, SC

\begin{tabular}{|c|c|c|c|c|}
\hline \multirow[b]{3}{*}{ Rootstock cultivar and treatment ${ }^{\mathrm{z}}$} & \multicolumn{4}{|c|}{ Wilt incidence $(\%)^{\mathrm{w}}$} \\
\hline & \multicolumn{2}{|c|}{ Early season ${ }^{x}$} & \multicolumn{2}{|c|}{ Late season $^{y}$} \\
\hline & 2010 & 2011 & 2010 & 2011 \\
\hline Tri-X 313 self-grafted & $62.4 \mathrm{a}$ & $9.3 \mathrm{ab}$ & $68.6 \mathrm{a}$ & $25.6 \mathrm{ab}$ \\
\hline Tri-X 313, nongrafted & $36.9 \mathrm{ab}$ & $8.0 \mathrm{ab}$ & $45.8 \mathrm{bc}$ & $52.9 \mathrm{a}$ \\
\hline Ojakkyo grafted & $51.5 \mathrm{ab}$ & $19.7 \mathrm{a}$ & $55.6 \mathrm{ab}$ & $21.9 \mathrm{~b}$ \\
\hline Strong Tosa grafted & $34.0 \mathrm{~b}$ & $0.9 \mathrm{bc}$ & $44.4 \mathrm{bc}$ & $0.8 \mathrm{c}$ \\
\hline Shintosa Camel grafted & $31.3 \mathrm{~b}$ & $0.2 \mathrm{c}$ & $41.7 \mathrm{bc}$ & $0.2 \mathrm{c}$ \\
\hline WMXP 3945 grafted & $26.5 \mathrm{~b}$ & $1.1 \mathrm{bc}$ & $37.5 \mathrm{bc}$ & $1.9 \mathrm{c}$ \\
\hline Macis grafted & $46.7 \mathrm{ab}$ & $0.2 \mathrm{c}$ & $48.6 \mathrm{bc}$ & $1.7 \mathrm{c}$ \\
\hline Emphasis grafted & $29.2 \mathrm{~b}$ & $0.0 \mathrm{c}$ & $31.9 \mathrm{c}$ & $0.2 \mathrm{c}$ \\
\hline$P$ value & 0.0059 & 0.0001 & 0.0250 & 0.0001 \\
\hline
\end{tabular}

${ }^{w}$ Means are least-squares means back-transformed from arcsine of the square root values used in the analysis of variance, except for 2010 late-season incidence data, which did not require transformation. Means within a column followed by the same letter are not significantly different based on $t$ tests at $P$ $\leq 0.01$, except for final wilt incidence in 2010 , where $P \leq 0.05$.

${ }^{x}$ Early season ratings were taken 18 days after transplanting in 2010 and 19 days after transplanting in 2011.

y Late season ratings were taken 48 days after transplanting in each of 2010 and 2011.

${ }^{\mathrm{z}}$ Refer to Table 1 for details of each cucurbit cultivar. 
two distinct patterns. In the first pattern, susceptible cultivars of watermelon and Ojakkyo citron yielded $F$. oxysporum frequently from bases and tops or scions, whereas recovery from bottlegourd and interspecific hybrid squash was infrequent or less frequent. This pattern was observed in all four experiments with grafted plants and in the two experiments with nongrafted rootstock cultivars inoculated with race 1 of $F$. oxysporum $\mathrm{f}$. sp. niveum. The second pattern was uniform infection of the bases of nongrafted plants of both susceptible and resistant cultivars by race 2 but with less frequent infection of the tops of resistant cultivars. Thus, the race 2 isolate used in these experiments was capable of infecting the bases of rootstocks more frequently than the race 1 isolate used. Race 2 isolates have been reported to be more virulent on watermelon than race 1 isolates $(29,45)$. It appears that this virulence includes a greater degree of colonization of asymptomatic hosts (28).

To determine whether grafted plants have been infected by $F$. oxysporum f. $\mathrm{sp}$. niveum, sampling from the scion is more likely to yield pathogenic isolates than sampling from the rootstock, based on results of this study. Based on the greenhouse results, $69 \%$ of the isolates recovered from the tops or scions of inoculated plants were pathogenic, while only $28 \%$ of the isolates recovered from the bases of inoculated plants were pathogenic. In a smaller sample of isolates that were collected from the field in 2006, 50\% of the isolates from scions or tops were pathogenic.

The different results in the 2010 and 2011 field experiments, in which initial inoculum levels differed greatly, paralleled results reported by Martyn and McLaughlin (31) for nongrafted watermelon and by Caperton et al. (2) for yellow summer squash. When both crops were inoculated with race 1 of $F$. oxysporum f. sp. niveum, cultivars appeared more susceptible as the inoculum density increased. The frequency of infection of scions was greater in the field in 2010 than in the greenhouse experiments, where infection of scions grafted onto bottlegourd and interspecific hybrid squash rootstocks was infrequent. It is likely that continuous exposure of roots to inoculum in the root zone of the transplants in the field increased the frequency of infection compared with a brief dipping of roots into a suspension of microconidia of the pathogen in the greenhouse. Infection of bottlegourd and interspecific hybrid squash was similar to the observations reported by Martyn and McLaughlin (32) and summarized by Martyn (30), in that some isolates of $F$. oxysporum $\mathrm{f}$. sp. niveum could infect melon, cucumber, and summer squashes (C. pepo), and young host plants (other than watermelon) were more susceptible than older plants. Zhou and Everts (48) found that 4 of 88 isolates of $F$. oxysporum f. sp. niveum were pathogenic on muskmelon (Cucumis melo) seedlings. One of these isolates caused a moderate level of wilt (20 to $35 \%$ incidence) on mature muskmelon plants in the field.

Despite colonization of the plants by $F$. oxysporum $\mathrm{f}$. sp. niveum in some experiments, the five cultivars of bottlegourd and interspecific hybrid squash tested in this study can be considered resistant

Table 4. Mean yield across experiments in spring 2010 and spring 2011 of seedless watermelon Tri-X 313 grafted onto six cucurbit rootstocks and control watermelon treatments in a field infested with Fusarium oxysporum f. sp. niveum in Charleston, $\mathrm{SC}^{\mathrm{y}}$

\begin{tabular}{lccc}
\hline $\begin{array}{l}\text { Rootstock cultivar, } \\
\text { treatment }\end{array}$ & $\begin{array}{c}\text { Fruit weight } \\
\text { (Mg/ha) }\end{array}$ & $\begin{array}{c}\text { Fruit } \\
\text { number/ha }\end{array}$ & $\begin{array}{c}\text { Average fruit } \\
\text { weight }(\mathbf{k g})\end{array}$ \\
\hline Emphasis grafted & $51.0 \mathrm{a}$ & $7,303 \mathrm{a}$ & $7.09 \mathrm{~b}$ \\
Macis grafted & $48.8 \mathrm{ab}$ & $6,883 \mathrm{ab}$ & $7.15 \mathrm{~b}$ \\
WMXP 3945 grafted & $47.6 \mathrm{ab}$ & $6,661 \mathrm{abc}$ & $7.28 \mathrm{~b}$ \\
Strong Tosa grafted & $46.6 \mathrm{ab}$ & $6,219 \mathrm{abcd}$ & $7.53 \mathrm{ab}$ \\
Shintosa Camel grafted & $40.5 \mathrm{bc}$ & $5,511 \mathrm{~cd}$ & $7.43 \mathrm{ab}$ \\
Ojakkyo grafted & $43.0 \mathrm{abc}$ & $5,555 \mathrm{~cd}$ & $7.83 \mathrm{a}$ \\
Tri-X 313, nongrafted & $35.8 \mathrm{c}$ & $5356 \mathrm{~cd}$ & $6.57 \mathrm{c}$ \\
Tri-X 313 self-grafted & $33.2 \mathrm{c}$ & $5179 \mathrm{~d}$ & $6.45 \mathrm{c}$ \\
Pooled standard error & 3.7 & 480 & 0.18 \\
\hline
\end{tabular}

${ }^{\mathrm{y}}$ Means within a column followed by the same letter are not significantly different at $P \leq 0.05$.

${ }^{\mathrm{z}}$ Refer to Table 1 for details of each cucurbit cultivar. to this pathogen (i.e., did not show symptoms of wilting) and, in the greenhouse, had little to no recovery of $F$. oxysporum from the tops of plants. A limited incidence of recovery of $F$. oxysporum $\mathrm{f}$. sp. niveum from the upper portion of stems of resistant watermelon cultivars has been reported (46). Cucurbita moschata and C. maxima, the parents of interspecific hybrid squash rootstocks, previously were shown to be resistant to $F$. oxysporum $\mathrm{f}$. $\mathrm{sp}$. niveum (33). Similarly, in a greenhouse study in Turkey, Macis, Emphasis, and Strong Tosa were listed as resistant to F. oxysporum f. sp. niveum races 0,1 , and 2 (44). In an infested field, watermelon grafted onto interspecific hybrid squash rootstocks, including Strong Tosa, and bottlegourd rootstocks, including Emphasis, showed no symptoms, whereas 5 to $10 \%$ of the nongrafted watermelon plants did develop symptoms (44). In contrast, Macis and Strong Tosa (referred to as Strong Toza in that study) evaluated as rootstocks and grafted plants were susceptible to three isolates of $F$. oxysporum f. sp. niveum from Tunisia, whereas Emphasis and Shintosa Camel (referred to as S. Camel) were resistant to very resistant (1). Macis and Emphasis were listed as cultivars of interspecific hybrid squash, which was assumed to be an error in that report (1).

Watermelon grafted onto Ojakkyo had moderate to severe Fusarium wilt incidence in the field and greenhouse experiments in this study and frequently was colonized by $F$. oxysporum $\mathrm{f}$. sp. niveum in the greenhouse trials. Because citron has greater resistance to Meloidogyne incognita than L. siceraria, hybrid Cucurbita, or watermelon, citron rootstocks could be useful in fields infested with southern root-knot nematodes (39). However, before being used in fields infested with $F$. oxysporum $\mathrm{f}$. sp. niveum, citron rootstock cultivars must be screened for resistance to $F$. oxysporum $\mathrm{f}$. sp. niveum. Based on a recent report of a high level of resistance to Fusarium wilt caused by race 2 in citron United States Department of Agriculture Plant Introduction genotypes, it should be possible to find resistant lines that could be used as rootstocks (42).

With watermelon, an increase in yield based on marketable fruit weight results from an increase in the number of marketable fruit, the size of marketable fruit, or both (13). The increase in marketable fruit weight produced by watermelon grafted onto bottlegourd observed in this study mainly was due to an increase in the number of fruit, not an increase in the size of fruit. The same result was obtained in field trials in Turkey with a diploid watermelon cultivar grafted onto the bottlegourd rootstock 'Skopje' and planted into soil with a low inoculum level of $F$. oxysporum $\mathrm{f}$. sp. niveum $(43,44)$. In addition, grafting onto Emphasis increased the number

Table 5. Recovery of Fusarium oxysporum from the base of the rootstock and the Tri-X 313 scion of grafted watermelon plants inoculated at transplanting with a mixture of races 1 and 2 of $F$. oxysporum $\mathrm{f}$. sp. niveum and that developed symptoms of wilting in spring 2010 in a field site in Charleston, SC

\begin{tabular}{|c|c|c|c|}
\hline \multirow[b]{2}{*}{$\begin{array}{l}\text { Rootstock cultivar, } \\
\text { treatment }^{\mathrm{z}}\end{array}$} & \multicolumn{3}{|c|}{ Recovery (\%) of F. oxysporum ${ }^{y}$} \\
\hline & $\begin{array}{c}\text { Top } \\
\text { of plant }\end{array}$ & $\begin{array}{c}\text { Base } \\
\text { of plant }\end{array}$ & $\begin{array}{l}\text { Top and base } \\
\text { of same plant }\end{array}$ \\
\hline Tri-X 313, nongrafted & 100 & 100 & 100 \\
\hline Tri-X 313 self-grafted & 50 & 100 & 50 \\
\hline Ojakkyo grafted & 67 & 83 & 67 \\
\hline Shintosa Camel grafted & 33 & 33 & 33 \\
\hline Strong Tosa grafted & 50 & 50 & 33 \\
\hline Macis grafted & 17 & 83 & 17 \\
\hline Emphasis grafted & 33 & 83 & 33 \\
\hline WMXP 3945 grafted & 40 & 40 & 40 \\
\hline Mean percentage & 48.9 & 72.3 & 46.8 \\
\hline Total & $(n=23)$ & $(n=34)$ & $(n=22)$ \\
\hline
\end{tabular}

y Recovery was based on culturing symptomatic vines from 47 plants, six plants per cultivar, one plant from each field replication, except for WMXP 3945, which had symptomatic plants in only five replications when sampling was done on 28 April and 7 May 2010. Refer to the main text for details on the isolation method.

${ }^{\mathrm{z}}$ Refer to Table 1 for details of each cucurbit cultivar. Total = total number of plants yielding $F$. oxysporum isolates. 
of fruit per plant and total weight of fruit but not the percentage of marketable fruit (44). Seeded watermelon grafted onto bottlegourd rootstocks generally produced larger fruit than watermelon grafted onto interspecific hybrid squash rootstocks or the nongrafted control watermelon plants; however, the difference was significant only with Skopje $(43,44)$. In addition to the yield increase observed from grafting onto bottlegourd, one interspecific squash cultivar in this study, Strong Tosa, also increased marketable weight and fruit size but not fruit number. Similarly, in Spain, rootstocks of interspecific hybrid squash and $C$. moschata increased marketable weight of grafted seedless watermelon in soil severely infested with Fusarium spp. compared with the three control treatments of a watermelon rootstock, a bottle gourd rootstock, and nongrafted plants (33). The interspecific hybrid squash rootstock 'Shintoza' consistently increased fruit size compared with nongrafted seedless watermelon (33). However, in Turkey, grafting onto Strong Tosa did not increase number of fruit per plant or total yield (44).

The increased returns obtained with watermelon grafted onto bottlegourd rootstocks could help offset the increased costs of grafted transplants compared with conventional, nongrafted transplants $(3,22)$. Nongrafted transplants cost $\$ 0.21$ each in South Carolina and, at standard plant populations of 4,940/ha in the southeastern United States, represent $\$ 1,037$ of the $\$ 7,705 /$ ha production costs (8). Grafted transplants are estimated to cost three times as much as nongrafted transplants, which is approximately $\$ 0.63$ apiece or $\$ 3,112 /$ ha if 4,940 transplants/ha are set (4). The increase in crop value of $\$ 3,617 /$ ha with a bottlegourd rootstock (based on the average price of $\$ 0.27 / \mathrm{kg}$ for watermelon in South Carolina between 2009 and 2011) would cover the additional cost of grafted watermelon transplants, $\$ 2,075 / \mathrm{ha}$, and leave $\$ 1,542 / \mathrm{ha}$ in additional returns above those expected from a nongrafted cultivar susceptible to Fusarium wilt grown in an infested field $(8,40)$. In Israel, growers have been able to reduce the number of grafted watermelon plants transplanted per hectare due to increased fruit production on grafted compared with nongrafted plants; this is another option for improving the cost-benefit ratio of grafted watermelon (3).

\section{Acknowledgments}

We thank V. DuBose, M. Schaffer, R. Hayes, and G. Baccari for technical assistance; and Syngenta, Nunhems, and Harris Moran for donating seed.

\section{Literature Cited}

1. Boughalleb, N., Tarchoun, N., El Mbarki, A., and El Mahjoub, M. 2007. Resistance evaluation of nine cucurbit rootstocks and grafted watermelon (Citrullus lanatus L.) varieties against Fusarium wilt and Fusarium crown and root rot. J. Plant Sci. 2:102-107.

2. Caperton, C. M., Martyn, R. D., and Starr, J. L. 1986. Effects of Fusarium inoculum density and root-knot nematodes on wilt resistance in summer squash. Plant Dis. 70:207-209.

3. Cohen, R., Burger, Y., Horev, C., Koren, A., and Edelstein, M. 2007. Introducing grafted cucurbits to modern agriculture: the Israeli experience. Plant Dis. 9:916-923.

4. Davis, A. R., Perkins-Veazie, P., Sakata, Y., Lopez-Galarza, S., Maroto, J. V., Lee, S. G., Huh, Y. C., Sun, Z., Miguel, A., King, S. K., Cohen, R., and Lee, J. M. 2008. Cucurbit grafting. Crit. Rev. Plant Sci. 27:50-74.

5. Diener, A. 2012. Visualizing and quantifying Fusarium oxysporum in the plant host. Mol. Plant-Microbe Interact. 25:1531-1541.

6. Egel, D. S., and Martyn, R. D. 2007. Fusarium wilt of watermelon and other cucurbits. The Plant Health Instructor. Online publication. doi:10.1094/PHII-2007-0122-01

7. Egel, D. S., Nowaskie, D., and Hoke, S. 2012. Evaluation of fungicides for the management of early blight and bacterial spot on tomato, 2011. Plant Dis. Manage. Rep. 6:V028. Online publication. doi:10.1094/PDMR06

8. Ferreira, W. 2013. Enterprise Budgets: Watermelons-on plastic-dripirrigation-seedless. Clemson Cooperative Extension, Clemson, SC. Online publication.

9. Gargouri, S., Hajlaoui, M. R., Abdennadher, M., and Marrakchi, M. 2000. Isolement et identification morphologique et moléculaire des espèces de Fusarium transmises par les semences de pastèque. EPPO Bull. 30:217-222.

10. Guan, W., and Zhao, X. 2012. Defense mechanisms involved in disease resistance of grafted vegetables. HortScience 47:164-170.

11. Hassell, R. L., Memmott, F., and Liere, D. G. 2008. Grafting methods for watermelon production. HortScience 4:1677-1679.

12. Hopkins, D. L., Lobinske, R. J., and Larkin, R. P. 1992. Selection for Fusarium oxysporum f. sp. niveum race 2 in monocultures of watermelon resistant to Fusarium wilt. Phytopathology 82:290-293.

13. Keinath, A. P. 2001. Effect of fungicide applications scheduled to control gummy stem blight on yield and quality of watermelon fruit. Plant Dis 85:53-58.

14. Keinath, A. P., and DuBose, V. B. 2009. First report of Fusarium oxysporum f. sp. niveum race 2 in South Carolina watermelon fields. (Abstr.) Phytopathology 99:S63.

15. Keinath, A. P., and Hassell, R. L. 2009. On-farm evaluation of hairy vetch and fumigation for integrated control of Fusarium wilt on seedless watermelon. Plant Dis. Manage. Rep. 3:V035. Online publication. doi:10.1094/ PDMR03

16. Keinath, A. P., Hassell, R. L., and DuBose, V. B. 2006. Evaluation of min and pollenizer watermelons for susceptibility to Fusarium wilt, powdery mildew, and gummy stem blight. Biol. Cult. Tests 21:V002. Online publication. doi:10.1094/BC21

17. Keinath, A. P., Hassell, R. L., and DuBose, V. B. 2012. Field evaluation of six cucurbit rootstocks to manage Fusarium wilt on triploid watermelon, 2011. Plant Dis. Manage. Rep. 6:V024. Online publication. doi:10.1094/ PDMR06

18. Keinath, A. P., Hassell, R. L., Everts, K. L., and Zhou, X.-G. 2010. Cover crops of hybrid common vetch reduce Fusarium wilt of seedless watermelon in the eastern United States. Plant Health Progress. Online publication. doi:10.1094/PHP-2010-0914-01-RS

19. King, S. R., Davis, A. R., Liu, W., and Levi, A. 2008. Grafting for disease resistance. HortScience 43:1673-1676.

20. Komada, H. 1975. Development of a selective medium for quantitative isolation of Fusarium oxysporum from natural soils. Rev. Plant Prot. Res. 8:114-124.

21. Kleczewski, N. M., and Egel, D. S. 2011. A diagnostic guide for Fusarium wilt of watermelon. Plant Health Progress. Online publication. doi:10.1094/ PHP-2011-1129-01-DG

22. Kubota, C., McClure, M. A., Kokalis-Burelle, N., Bausher, M. G., and Rosskopf, E. N. 2008. Vegetable grafting: history, use, and current technology status in North America. HortScience 43:1664-1669.

23. Kuldau, G. A., and Yates, I. E. 2000. Evidence for Fusarium endophytes in cultivated and wild plants. Pages 85-117 in: Microbial Endophytes. C. W. Bacon and J. F. White, eds. Marcel Dekker, Inc., New York.

24. Kuniyasu, K., and Takeuchi, S. 1983. Wilt of watermelon grafted on bottle gourd rootstocks inoculated with Fusarium oxysporum f. sp. lagenariae. Bull. Veg. Ornamental Crops Res. Stn. Ser. A 11:139-140. (In Japanese, with English summary)

25. Larkin, R. P., Hopkins, D. L., and Martin, F. N. 1996. Suppression of Fusarium wilt of watermelon by nonpathogenic Fusarium oxysporum and other microorganisms recovered from a disease-suppressive soil. Phytopathology 86:813-819.

26. Lee, J.-M. 1994. Cultivation of grafted vegetables I. Current status, grafting methods, and benefits. HortScience 29:235-239.

27. Louws, F. J., Rivard, C. L., and Kubota, C. 2010. Grafting fruiting vegetables to manage soilborne pathogens, foliar pathogens, arthropods and weeds. Sci. Hortic. Amsterdam 127:127-146.

28. Malcolm, G. M., Kuldau, G. A., Gugino, B. K., and Jiménez-Gasco, M. M. 2013. Hidden host plant associations of soilborne fungal pathogens: an ecological perspective. Phytopathology 103:538-544.

29. Martyn, R. D. 1987. Fusarium oxysporum f. sp. niveum race 2: a highly aggressive race new to the United States. Plant Dis. 71:233-236.

30. Martyn, R. 1996. Fusarium wilt of watermelon. Pages 13-14 in: Compendium of Cucurbit Diseases, T. A. Zitter, C. E. Thomas, and D. L. Hopkins, eds. American Phytopathological Society, St. Paul, MN.

31. Martyn, R. D., and McLaughlin, R. J. 1983. Susceptibility of summer squash to the watermelon wilt pathogen (Fusarium oxysporum f. sp. niveum). Plant Dis. 67:263-266.

32. Martyn, R. D., and McLaughlin, R. J. 1983. Effects of inoculum concentration on the apparent resistance of watermelons to Fusarium oxysporum $\mathrm{f}$. sp. niveum. Plant Dis. 67:493-495

33. Miguel, A., Varoto, J. V., San Bautista, A., Baizauli, C., Cebolla, V., Pascual, B., López, S., and Guardiola, J. L. 2004. The grafting of triploid watermelon is an advantageous alternative to soil fumigation by methyl bromide for control of Fusarium wilt. Sci. Hortic. Amsterdam 103:9-17.

34. Motsenbocker, C. E., and Arancibia, R. A. 2002. In-row spacing influences triploid watermelon yield and crop value. HortTechnology 12:437-440.

35. Njoroge, S. M. C., Riley, M. B., and Keinath, A. P. 2008. Effect of incorporation of Brassica spp. residues on population densities of soilborne microorganisms and on damping-off and Fusarium wilt of watermelon. Plant Dis. 92:287-294.

36. Orton, W. A., and Meier, F. C. 1922. Diseases of watermelons. U. S. Dep. Agric. Farm. Bull. 1277.

37. Santner, T. J., and Duffy, D. E. 1989. The Statistical Analysis of Discrete Data. Springer-Verlag, New York.

38. Steele, R. G. D., and Torrie, J. H. 1980. Principles and Procedures of Statistics: A Biometrical Approach, 2nd ed. McGraw Hill Book Company, New York.

39. Thies, J. A., Ariss, J. J., Hassell, R. L., Olson, S., Kousik, C. S., and Levi, A. 2010. Grafting for management of southern root-knot nematode, Meloidogyne incognita, in watermelon. Plant Dis. 94:1195-1199. 
40. United States Department of Agriculture, National Agricultural Statistics Service. 2012. Vegetables 2011 Summary (January 2012). http://usda. mannlib.cornell.edu/MannUsda/viewDocumentInfo.do?documentID=1183

41. United States Environmental Protection Agency. 2013. Implementation of risk mitigation measures for soil fumigant pesticides. http://www.epa.gov/ oppsrrd1/reregistration/soil_fumigants/

42. Wechter, W. P., Kousik, C., McMillan, M., and Levi, A. 2012. Identification of resistance to Fusarium oxysporum f. sp. niveum race 2 in Citrullus lanatus var. citroides Plant Introductions. HortScience 47:334-338.

43. Yetisir, H., and Sari, N. 2003. Effect of different rootstocks on plant growth, yield and quality of watermelon. Aust. J. Exp. Agric. 43:1269-1274.

44. Yetisir, H., Sari, N., and Yücel, S. 2003. Rootstock resistance to Fusarium wilt and effect on watermelon fruit yield and quality. Phytoparasitica 31:163-169.
45. Zhou, X. G., and Everts, K. L. 2003. Races and inoculum density of Fusarium oxysporum f. sp. niveum in commercial watermelon fields in Maryland and Delaware. Plant Dis. 87:692-698.

46. Zhou, X. G., and Everts, K. L. 2004. Quantification of root and stem colonization of watermelon by Fusarium oxysporum f. sp. niveum and its use in evaluating resistance. Phytopathology 94:832-841.

47. Zhou, X. G., and Everts, K. L. 2004. Suppression of Fusarium wilt of watermelon by soil amendment with hairy vetch. Plant Dis. 88:1357-1365.

48. Zhou, X. G., and Everts, K. L. 2007. Characterization of a regional population of Fusarium oxysporum $\mathrm{f}$. sp. niveum by race, cross pathogenicity, and vegetative compatibility. Phytopathology 97:461-469.

49. Zhou, X. G., Everts, K. L., and Bruton, B. D. 2010. Race 3, a new and highly virulent race of Fusarium oxysporum $\mathrm{f}$. sp. niveum causing Fusarium wilt in watermelon. Plant Dis. 94:92-98. 